\title{
Application of Weibull model for survival of patients with gastric cancer
}

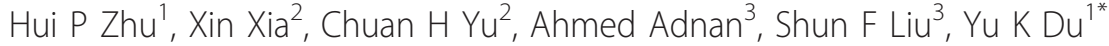

\begin{abstract}
Background: Researchers in the medical sciences prefer employing Cox model for survival analysis. In some cases, however, parametric methods can provide more accurate estimates. In this study, we used Weibull model to analyze the prognostic factors in patients with gastric cancer and compared with Cox.

Methods: We retrospectively studied 1715 patients with gastric cancer. Age at diagnosis, gender, family history, past medical history, tumor location, tumor size, eradicative degree of surgery, depth of tumor invasion, combined evisceration, pathologic stage, histologic grade and lymph node status were chosen as potential prognostic factors. Weibull and Cox model were performed with hazard rate and Akaike Information Criterion (AIC) to compare the efficiency of models.

Results: The results from both Weibull and Cox indicated that patients with the past history of having gastric cancer had the risk of death increased significantly followed by poorly differentiated or moderately differentiated in histologic grade. Eradicative degree of surgery, pathologic stage, depth of tumor invasion and tumor location were also identified as independent prognostic factors found significant. Age was significant only in Weibull model.
\end{abstract}

Conclusion: From the results of multivariate analysis, the data strongly supported the Weibull can elicit more precise results as an alternative to Cox based on AIC.

\section{Background}

Gastric carcinoma (GC) is one of the leading causes of cancer-related death in the world [1-3], and it is the most common malignant tumor in Asia, Eastern Europe, and South America $[4,5]$. In Japan, stomach cancer ranks the first place in women and the second place in men with respect to the cause of death from malignant tumor [6,7]. Although age-standardized mortality rate of GC has decreased in China now, it is still the third most common causes of death in men after lung and liver cancer, and the fifth in women. For locally advanced gastric cancer patients, the 5-year survival rate is below $20 \%$ and it is about $30 \%$ for those undergoing surgical treatment. Even after taking curative resections, only 30 $50 \%$ of the patients can survive after 5 years $[8,9]$. In terms of treatment for gastric cancer, surgery is considered as the best way for achieving good outcomes [10].

\footnotetext{
* Correspondence: birdping@163.com

'Department of Maternal and Child Health, School of Public Health, Tongji Medical College, Huazhong University of Science and Technology, Wuhan, PR China

Full list of author information is available at the end of the article
}

However, there are still lots of challenges for gastrointestinal doctors to conquer. It is estimated that at least $80 \%$ of patients recur disease even after they took curative gastric resections. Previous studies tried to find out clinic-pathological factors and socio-demographic characteristics associated with high recurrence rate. These studies had drawn conflicting results with respect to independent prognostic factors affecting survival of patients with GC [1].

Parametric methods which include the exponential, Weibull, lognormal, gamma and extreme value distributions have been widely used in fitting survival data [11]. Cox semi-parametric method [12] has also been extensively used for modeling such data. These methods are presented to account for the relationship between survival and some concomitant variables such as age, gender, family history of gastric cancer, or diagnostic characteristics. Actually, in the medical sciences, researchers lean to use Cox semi-parametric method instead of parametric methods to analyze survival data. For example, there were studies that have been done to assess the effect of clinic-pathological and demographic factors on
C Biomed Central

() 2011 Zhu et al; licensee BioMed Central Ltd. This is an Open Access article distributed under the terms of the Creative Commons Attribution License (http://creativecommons.org/licenses/by/2.0), which permits unrestricted use, distribution, and reproduction in any medium, provided the original work is properly cited. 
survival of patients with stomach cancer using Cox model to find pertinent relationship between survival time and the variables [13-15]. The primary reason is that there seem to be fewer assumptions in the use of Cox semi-parametric method. In some circumstances, however, parametric methods can provide more accurate estimates [16,17]. Many of the parametric models such as Weibull are accelerated failure time models. Weibull allows more flexibility than the Cox semi-parametric model because the associated hazard rate is not constant with respect to time. Also, we use maximum likelihood process to estimate the unknown parameters and its interpretation and technique are familiar for researchers.

In this study, we aimed to evaluate the potential prognostic factors that may affect the survival of patients with gastric cancer employing Weibull model, and to compare analytic results with Cox's proportional hazard model.

\section{Methods}

\section{Data Sources}

We reviewed hospital database of 1,814 patients with gastric cancer who underwent surgical treatment in Tongji hospital in Wuhan, China, during the years 1995 to 2006. We retrospectively reviewed their medical records and excluded 99 patients for incomplete medical document. Finally, 1,715 patients were enrolled in our study. Thereafter, all the patients were observed through a programmed followed-up schedule. Survival information was collected through telephone interviews with patients and/or their relatives who were at home at the time of interview. This study was approved by the Ethics Committee of Huazhong University of Science \& Technology.

Gastric cancer stage was evaluated according to the International Union Against Cancer (UICC) TNM classification of malignant tumors [18]. Survival analysis was based on the clinical and pathologic variables, which were sub-layered into family history of GC, histologic grade (well, moderately and poorly differentiation), tumor location (upper, middle and lower) in the stomach, the stage of the carcinoma (I, II, III, IV), depth of tumor penetration (T1, T2, T3, and T4) as defined by the American Joint Committee on Cancer (AJCC), N categories on the basis of the number of metastatic lymph nodes (pN0: 0, pN1: 1-6, pN2: 7-15, pN3: > 15) defined by the International Union Against Cancer (UICC) and the American Joint Committee on Cancer (AJCC) in the 5th edition of the TNM system in 1997 [19].

\section{Statistical Analysis}

Statistic calculations were performed using statistical software SAS, version 9.1. Quantitative result was expressed as the mean \pm standard deviation (SD).
Univariate analysis was conducted using the Kruskalwallis and $t$ test. Differences at $P<0.05$ were considered significant. Covariates that were identified as significant factors throughout the univariate analysis were selected for multivariate analysis, which was performed employing Weibull and Cox's proportional hazard model to build the prognostic indicators of survival in patients with gastric cancer. A plot of the log of the negative log of the estimated survivor function against log time (by specifying LLS) was drawn. LLS plot can provide a visual check of the appropriateness of the Weibull model for the survival data [20]. HR (hazard rate) and the AIC (Akaike Information Criterion) were used to compare the efficiency of models between Weibull and Cox model. The AIC is a measure of the goodness of fit of the model estimated that proposed by Akaike in 1974 [21] and is a practical way of trading off the complexity of an estimated model against how well the model fits the data. Lower AIC indicates better likelihood.

\section{Results}

\section{Clinical and pathologic features}

Patient characteristics were detailed in Table 1. A total number of 1715 patients with gastric cancer entered to this study, 465(27.1\%) were women and $1250(72.9 \%)$ man. The mean age at diagnosis was $57.5 \pm 10.9$ years (range $=21 \sim 90$ years). Evidence of family history and past history of GC were seen in 284 patients $(16.6 \%)$ and 457 patients $(26.6 \%)$ respectively. Of the total patients, 1315 patients $(78.8 \%)$ had tumour size $\geq 40 \mathrm{~mm}, 492$ patients $(28.7 \%)$ diagnosed with stage IV of gastric cancer. Tumors were located in the lower third stomach in 1086 patients $(63.3 \%)$, in the middle third of the stomach in 281 patients $(16.4 \%)$, in the upper third stomach in 193 patients (11.3\%), and whole stomach 155 patients (9.0\%). Among all the patients, 809 (47.8\%) patients received utterly eradicative degree of surgery. Tumors were classified as well differentiated in 521 patients (30.3\%), moderately differentiated in 253 patients (14.8\%), and poorly differentiated in 941 patients (54.9\%). Lymph node involvement defined by AJCC classifications included 629 patients with N0 category, 717 patients with N1 category, 272 patients with N2 category, and 97 patients with N3 category. AJCC T1 about depth of invasion was identified in 145 patients $(8.5 \%)$, AJCC T2 in 879 patients $(51.3 \%)$, AJCC T3 in 549 patients (32.0\%), and AJCC T4 in 142 patients (8.3\%).

\section{Distribution of the survival time}

Usually, a first step in the analysis of survival data is the estimation of the distribution of the survival time. Figure 1 displays the graph of the $\log (-\log$ (estimated survival function)) against log (failure time), i.e. LLS plot. If the Weibull model is appropriate, the LLS curve 
Table 1 Clinic-pathological characteristics of the patients with gastric cancer

\begin{tabular}{|c|c|c|c|}
\hline Factors & Categories & $\begin{array}{c}\text { No. of } \\
\text { patients (\%) }\end{array}$ & $\begin{array}{c}P \\
\text { value }\end{array}$ \\
\hline \multirow[t]{2}{*}{ Gender } & Female & $465(27.1)$ & 0.301 \\
\hline & Male & $1250(72.9)$ & \\
\hline age & & $57.5 \pm 10.9$ & $<0.001$ \\
\hline \multirow[t]{2}{*}{ Past medical history } & No & $1258(73.4)$ & 0.022 \\
\hline & Yes & $457(26.6)$ & \\
\hline \multirow{2}{*}{$\begin{array}{l}\text { Family history of } \\
\text { gastric cancer }\end{array}$} & No & $1431(83.4)$ & 0.431 \\
\hline & Yes & $284(16.6)$ & \\
\hline \multirow[t]{4}{*}{ Location of tumor } & Lower third & $1086(63.3)$ & $<0.001$ \\
\hline & Middle third & $281(16.4)$ & \\
\hline & Upper third & 193(11.3) & \\
\hline & Whole stomach & 155(9.03) & \\
\hline \multirow{3}{*}{$\begin{array}{l}\text { Eradicative degree } \\
\text { of surgery }\end{array}$} & Utterly & $809(47.8)$ & $<0.001$ \\
\hline & Relatively & $473(27.6)$ & \\
\hline & Palliative & $433(25.2)$ & \\
\hline \multirow[t]{2}{*}{ Tumor size(mm) } & $<40$ & $364(21.2)$ & $<0.001$ \\
\hline & $\geq 40$ & 1315(78.8) & \\
\hline \multirow[t]{4}{*}{ Stage } & । & $301(17.5)$ & $<0.001$ \\
\hline & $\|$ & $425(24.8)$ & \\
\hline & III & $497(29.0)$ & \\
\hline & IV & $492(28.7)$ & \\
\hline \multirow[t]{2}{*}{ Combined evisceration } & No & 1323(77.1) & $<0.001$ \\
\hline & Yes & $392(22.9)$ & \\
\hline \multirow[t]{3}{*}{ Histologic grade } & Well differentiated & $521(30.3)$ & $<0.001$ \\
\hline & $\begin{array}{c}\text { Moderately } \\
\text { differentiated }\end{array}$ & $253(14.8)$ & \\
\hline & $\begin{array}{c}\text { Poorly } \\
\text { differentiated }\end{array}$ & $941(54.9)$ & \\
\hline \multirow[t]{4}{*}{ Depth of invasion } & $\mathrm{T} 1$ & $145(8.5)$ & $<0.001$ \\
\hline & $\mathrm{T} 2$ & $879(51.3)$ & \\
\hline & T3 & $549(32.0)$ & \\
\hline & T4 & $142(8.3)$ & \\
\hline \multirow[t]{4}{*}{ Lymph node status } & NO & $629(36.7)$ & $<0.001$ \\
\hline & N1 & $717(41.8)$ & \\
\hline & N2 & $272(15.9)$ & \\
\hline & N3 & $97(5.7)$ & \\
\hline
\end{tabular}

$\mathrm{T} 1$, Tumour invades lamina propria or submucosa;

T2,Tumour invades muscularis propria or subserosa;

T3: Tumour penetrate serosa without invasion of adjacent structures;

T4: Tomour invades adjacent structures;

No, Metastasis in 0 regional lymph nodes;

$\mathrm{N} 1$, Metastasis in 1 to 6 regional lymph nodes;

N2, Metastasis in 7 to 15 regional lymph nodes;

$\mathrm{N} 3$, metastasis in more than 15 regional lymph nodes.

should be a straight line that does not necessarily go through the origin. This is because $S(t)=\exp (-($ la $t)$ $\wedge$ alpha) holds if $-\log S(t)=(\operatorname{la} t)^{\wedge}$ alpha, or if $\log (-\log S$ $(\mathrm{t}))=$ alpha $\log (\mathrm{la})+$ alpha $\log \mathrm{t}$. The slope of the line in the LLS plot is the Weibull shape parameter alpha and the intercept is alpha $\log$ (la). In this study, the lls plot

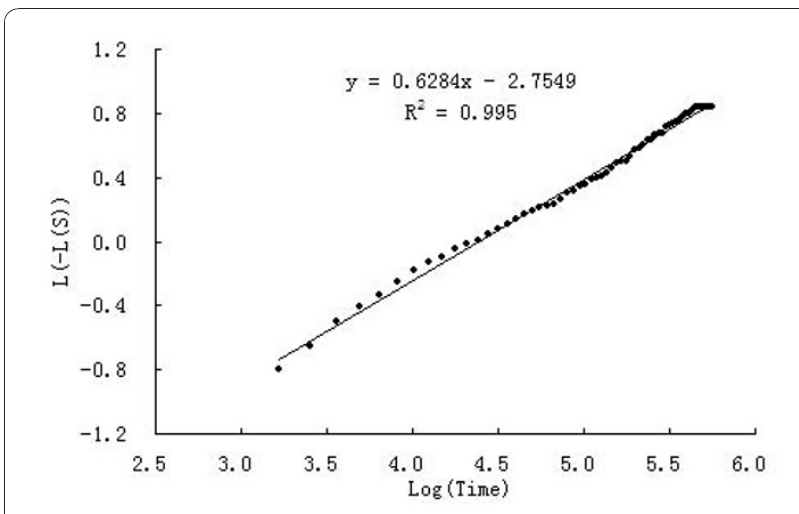

Figure 1 Log of negative Log survivor function estimates.

looks approximately linear which suggests graphically that the survival-time distribution considered is Weibull. Moreover, the value of intercept and scale were -3.324 and 1.362 , respectively, and alpha value is 0.734 given from SAS results.

\section{Multivariate Weibull and Cox Analysis of Prognostic Factors}

In univariate analysis, age $(P<0.001)$, past medical history $(P=0.022)$, tumor size $(P<0.001)$, histologic grade $(P<0.001)$, tumor location $(P<0.001)$, eradicative degree of $\operatorname{surgery}(P<0.001)$, tumor stage $(P<0.001)$, combined evisceration $(P<0.001)$, depth of invasion $(P$ $<0.001)$, and lymph node status $(P<0.001)$ were found significant factors that have influence on overall survival in all gastric cancer patients who underwent surgical treatment (Table 1). Variables shown to be of statistical significance in univariate survival analysis were further assessed by Weibull and Cox multivariate analysis. According to the results from both Cox and Weibull model patients with the past history of having gastric cancer had the risk of death increased significantly in term of hazard ratio in Cox regression and Weibull model followed by poorly differentiated and moderately differentiated in histologic grade $(P<0.05)$. Eradicative degree of surgery, pathologic stage, depth of tumor invasion and location of tumor were also identified as independent prognostic factors found significant. Age is significant in Weibull model but insignificant in Cox model for multivariate analysis (Table 2,3). Neither Cox nor Weibull model in both univariate and multivariate analysis show any evidence about significant differences in gender and family history of cancer. In multivariate models, the Weibull model had the best fit with respect to lower AIC (Table 3).

\section{Discussion}

In the field of medical sciences, researchers are interested in estimating the survival model with the vector of 
Table 2 Multivariate analysis of Weibull parametric model with prognostic factors

\begin{tabular}{|c|c|c|c|}
\hline Characteristics & $\beta$ & $\chi^{2}$ value & $P$ value \\
\hline Intercept & 0.76 & 0.53 & 0.467 \\
\hline Age & -0.03 & 6.27 & 0.012 \\
\hline Past medical history & -0.11 & 7.13 & 0.008 \\
\hline Location of tumor & - & 25.40 & $<0.001$ \\
\hline Lower third & 0.40 & 8.83 & 0.003 \\
\hline Middle third & 0.41 & 7.34 & 0.007 \\
\hline Upper third & -0.17 & 1.08 & 0.299 \\
\hline Whole stomach* & 0 & - & \\
\hline eradicative degree of surgery & - & 20.62 & $<0.001$ \\
\hline Utterly & 1.00 & 83.46 & $<0.001$ \\
\hline Relatively & 0.91 & 42.27 & $<0.001$ \\
\hline Palliative* & 0 & - & - \\
\hline Histologic grade & - & 12.51 & 0.002 \\
\hline Well differentiated & -0.08 & 0.80 & $<0.001$ \\
\hline Moderately differentiated & 0.34 & 9.30 & 0.082 \\
\hline Poorly differentiated* & 0 & - & - \\
\hline Depth of invasion & - & 49.11 & $<0.001$ \\
\hline $\mathrm{T} 1$ & 0.77 & 10.55 & 0.001 \\
\hline $\mathrm{T} 2$ & 0.22 & 2.48 & 0.115 \\
\hline $\mathrm{T} 3$ & 0.21 & 2.29 & 0.130 \\
\hline $\mathrm{T} 4^{*}$ & 0 & - & - \\
\hline Stage & - & 22.41 & $<0.001$ \\
\hline I & 0.62 & 8.27 & 0.004 \\
\hline ॥ & 0.76 & 21.22 & $<0.001$ \\
\hline III & 0.27 & 6.23 & 0.013 \\
\hline $\mathrm{IV}^{*}$ & 0 & - & - \\
\hline
\end{tabular}

*stands for a control group, and the rest compare with the control.

explanatory variables using Cox proportional hazard model more than parametric models. When conducting survival analysis employing Cox model, it is necessary to check the underlying assumptions. Cox model assumes that changes in levels of the independent variables will produce proportionate changes in the hazard function, independent of time. Also, it assumes a log-linear relationship between the hazard function and the time and any number of metric and/or nonmetric variables. In fact, however, assumptions that Cox proportional hazards modeling required may not be plausible in many situations [22], especially in biomedical field. If these assumptions do not hold, the Cox model will lead to unreliable conclusions. Unfortunately, according to Altman's review of survival analyses in cancer journals, only 5 percent of all studies using the Cox model check the underlying assumptions [23]. In the meantime, various parametric models such as Weibull and Lognormal had been developed to analyze survival data. These models can provide the interpretation based on specific distributions for survival time without need the proportional hazard assumptions. If survival times are Weibull
Table 3 Multivariate analysis of Cox and Weibull model with prognostic factors

\begin{tabular}{|c|c|c|}
\hline \multirow[t]{2}{*}{ Characteristics } & $\begin{array}{l}\text { Cox(AIC = } \\
4534.21)\end{array}$ & $\begin{array}{l}\text { Weilbull(AIC = } \\
\text { 1693.28) }\end{array}$ \\
\hline & HR (Cl: 95\%) & HR (Cl: 95\%) \\
\hline Age & $1.01(0.98-1.03)$ & $1.03 *(1.01-1.06)$ \\
\hline \multicolumn{3}{|l|}{ Past medical history } \\
\hline No & 1 & 1 \\
\hline Yes & $1.17^{*}(1.03-1.33)$ & $1.22^{*}(1.05-1.40)$ \\
\hline \multicolumn{3}{|l|}{ Location of tumor } \\
\hline Lower third & 1 & 1 \\
\hline Middle third & $0.93(0.74-1.18)$ & $0.99(0.86-1.25)$ \\
\hline Upper third & $1.47^{*}(1.12-1.93)$ & $1.35^{*}(1.19-1.53)$ \\
\hline Whole stomach & $1.45^{*}(1.08-1.93)$ & $1.47^{*}(1.21-1.75)$ \\
\hline \multicolumn{3}{|l|}{$\begin{array}{l}\text { eradicative degree } \\
\text { of surgery }\end{array}$} \\
\hline Utterly & 1 & 1 \\
\hline Relatively & 1.03 (0.77-1.39) & $1.79 *(1.64-1.92)$ \\
\hline Palliative & $2.16^{*}(1.71-2.73)$ & $4.07 *(3.85-4.34)$ \\
\hline \multicolumn{3}{|l|}{ Histologic grade } \\
\hline Well differentiated & 1 & 1 \\
\hline $\begin{array}{l}\text { Moderately } \\
\text { differentiated }\end{array}$ & $1.12^{*}(1.05-1.19)$ & $1.14 *(1.08-1.24)$ \\
\hline Poorly differentiated & $1.25^{*}(1.18-1.33)$ & $1.34^{*}(1.17-1.55)$ \\
\hline \multicolumn{3}{|l|}{ Depth of invasion } \\
\hline $\mathrm{T} 1$ & 1 & 1 \\
\hline $\mathrm{T} 2$ & $1.97^{*}(1.53-2.54)$ & $2.40 *(2.10-2.53)$ \\
\hline T3 & $2.19 *(1.68-2.86)$ & $2.77^{*}(2.53-2.96)$ \\
\hline T4 & $2.50^{*}(1.82-3.44)$ & $3.15 *(3.20-3.99)$ \\
\hline \multicolumn{3}{|l|}{ Stage } \\
\hline 1 & 1 & 1 \\
\hline$\|$ & $0.97(0.57-1.63)$ & $1.15(0.91-1.42)$ \\
\hline III & $1.57(0.97-2.56)$ & $1.93^{*}(1.66-2.25)$ \\
\hline IV & $2.06^{*}(1.21-3.51)$ & $3.03^{*}(2.76-3.80)$ \\
\hline
\end{tabular}

*significant at the 5\% level.

$\mathrm{HR}$, hazard ratio; $\mathrm{Cl}$, confidence interval.

AIC, akaike information criterion.

or exponentially distributed, the analysis using parametric methods is more powerful [16]. This means under certain circumstances, parametric models like Weibull, Exponential and Lognormal can elicit more accurate results than Cox model. Since population survival times are usually exponentially or Weibull distributed in the field of medicine, therefore, a parametric model will be more efficient and easier to specify than the corresponding semiparametric or nonparametric one and are more flexible as it allows easy incorporation of covariates. Several studies applying parametric models to evaluate prognostic factors affecting survival time of patients with cancer prove that parametric models offer advantages over Cox model $[16,24]$.

The purpose of this study was to explore the comparative performance of Weibull model and Cox model 
in a survival analysis of patients with gastric cancer. We used Akaike Information Criterion (AIC) to evaluate the two models. In a recent review of survival analyses, it was found that many studies have indicated clinical and pathologic characteristics of patients as explanatory variables with respect to survival [25-27]. In this study, we investigate the effects of age at diagnosis, gender, family history of cancer, past medical history, location of tumor, tumor size, eradicative degree of surgery, depth of tumor invasion, pathologic stage, histologic grade and lymph node status on survival time. Both Weibull and Cox multivariate analysis showed that with the past history of having gastric cancer, patients had significantly increased risk of death followed by the poorly differentiated and moderately differentiated in histologic grade. In addition, eradicative degree of surgery, pathologic stage, depth of tumor invasion and location of tumor were identified as independent prognostic factors of patients with GC as well. In our results, gender showed no impact on survival rate. But, some studies found that better survival rate for women [28], another reported that the consistently lower survival for stomach cancer among women [6].

Age at diagnosis was a strong and independent covariate for survival of patients with GC, and young patients had better survival as indicated by previous report [29]. Tumor size is a significant factor that had impact on the survival probability of patients in univariate analysis, which is similar to some other studies [30,31]. Depth of invasion was another outstanding prognostic indicator in both univariate and multivariate analysis. Our finding is in conformity with previous reports showed that depth of invasion has an influence on patient's survival $[32,33]$. Stage at diagnosis was strongly associated with prognosis in our study, which is a finding repeated in several other studies [34-36]. Previous reports have demonstrated that the number of metastatic lymph nodes was a powerful predictor of survival. Patients with metastases to 7 or more lymph nodes $(\mathrm{N} 2, \mathrm{~N} 3)$ had a notably worse outcome as opposed to patients with no lymph node metastases or metastases in 1 to 6 nodes $[1,2,37]$. However, our findings are not consistent with those previously reported showed by multivariate analysis. Furthermore, our study results suggested that histological classification was an independent predictor of survival.

In our study, age is significant in Weibull model, but it is insignificant in Cox regression for multivariate analysis. Cox model will only be used when the hazard rate is constant with respect to time, but from the Figure 1 in our study we can see that the survival-time distribution was Weibull distribution, so it is more accurate to use Weibull model. The evaluation criteria also indicated Weibull model to be more efficient in comparison to Cox in multivariate analysis. The findings strongly showed Weibull was the perfect model and might lead to more precise results.

\section{Conclusions}

Our study showed that age at diagnosis, past medical history, stage, eradicative degree of surgery, histologic grade, depth of tumor invasion and location of tumor were prognostic factors for survival in patients with GC. It can be concluded that the early detection of patients at younger age and in primary stages and histologic grade may have positive effect on patients with stomach cancer and be important to decrease the survival time. Also, from the results of multivariate analysis, the data strongly supported the Weibull model can elicit more precise results as an alternative to Cox.

\section{Acknowledgements}

The authors would like to thank Si-zhe Wang and Yan Guo for manuscript review. We also thank the department of data management of Tongji hospital for their help of data collection and the Expert Panel on Gastroenterologic Cancer Surgery for their contributions to the technical assistance.

\section{Author details}

'Department of Maternal and Child Health, School of Public Health, Tongji Medical College, Huazhong University of Science and Technology, Wuhan, PR China. ${ }^{2}$ Department of Epidemiology and Statistics, School of Public Health, Wuhan University, Wuhan, PR China. ${ }^{3}$ Department of General Surgery, Tongji Hospital, Tongji Medical College, Huazhong University of Science and Technology, Wuhan, PR China.

\section{Authors' contributions}

HPZ and XX participated in the design of the study and data collection and helped to draft the manuscript. $\mathrm{CHY}$ performed the statistical analysis. AA and SFL participated in data collection and drafted the manuscript. YKD conceived of the study, and participated in its design and coordination. All authors read and approved the final manuscript.

\section{Competing interests}

The authors declare that they have no competing interests.

Received: 25 August 2010 Accepted: 7 January 2011

Published: 7 January 2011

\section{References}

1. Mark ST, Simon PK, Katherine AY: Surgical outcomes of patients with gastric carcinoma: The importance of primary tumor location and microvessel invasion. Surgery 2003, 134:720-727.

2. Jemal A, Thomas A, Murray T, Thun M: Cancer statistics, 2002. CA Cancer J Clin 2002, 52:23-47.

3. Pourhoseingholi MA, Moghimi-Dehkordi B, Safaee A, Hajizadeh E, Solhpour A, Zali MR: Prognostic factors in gastric cancer using log-normal censored regression model. Indian J Med Res 2009, 129:262-267.

4. Toshiyasu O, Makoto I, Mikihito N: Association of Allogeneic Blood Transfusions and Long-Term Survival of Patients with Gastric Cancer after Curative Gastrectomy. J Gastrointest Surg 2009, 13:1821-1830.

5. Alberts SR, Cervantes A, Velde CJ, Gastric cancer: epidemiology, pathology and treatment. Ann Oncol 2003, 14(suppl2):ii31-36.

6. Naomi S, Yuri I, Akiko I: Gender Differences in Stomach Cancer Survival in Osaka, Japan:Analyses Using Relative Survival Model. Jpn J Clin Oncol 2009, 10:690-694.

7. Ministry of Health, Labour and Welfare: Tokyo: Vital Statistics of Japan. [http://ganjoho.ncc.go.jp/professional/statistics/odjrh3000000hwsa-att/ cancer_mortality], (1958-2006.xls) (30 March 2009, date last accessed). 
8. Jong-Han K, You-Jin J, Sung-Soo P: Surgical Outcomes and Prognostic Factors forT4 Gastric Cancers. J Asian Surg 2009, 32:198-204.

9. Neugut Al, Hayek M, Howe G: Epidemiology of gastric cancer. Semin Oncol 1996, 23:281-291.

10. Siewert JR, Bottcher K, Stein HJ: Relevant prognostic factors in gastric cancer: ten-year results of the German Gastric Cancer Study. Ann Surg 1998, 228:449-461

11. Alan JG: Parametric methods in the analysis of survival data. Microelectron Reliab 1980, 20:477-481.

12. Cox DR: Regression models and life-table. J Royal Stati Soci B 1972, 34:187-220.

13. Orsenigo E, Tomajer V, Palo SD, Carlucci M, Vignali A, Tamburini A: Impact of age on postoperative outcomes in 1118 gastric cancer patients undergoing surgical treatment. Gastric Cancer 2007, 10:39-44.

14. Zeraati H, Mahmoudi M, Kazemnejad A, Mohammed K: Postoperative life expectancy in gastric cancer patients and its associated factors. Saudi Med J 2005, 26:1203-1207.

15. Ming Z, Guan YZ, Yan M: Comparison of Four Staging Systems of Lymph Node Metastasis in Gastric Cancer. World I Surg 2009, 33:2383-2388.

16. Pourhoseingholi MA, Hajizadeh E, Moghimi-Dehkordi B, Safaee A, Abadi A Zali MR: Comparing Cox regression and parametric models for survival of patients with gastric carcinoma. Asian Pac J Cancer Prev 2007, 8:412-416.

17. Efron B: The efficiency of Cox's likelihood function for censored data. J Am Stati Associ 1977, 72:557-565.

18. Sobin $L H$, Wittekind C: TNM classification of malignant tumours. International Union Against Cancer. New York, Wiley-Liss; 62002

19. Fleming ID, Cooper JS, Henson DE: AJCC cancer staging manual. JB Philadelphia, Lippincott; 51997

20. Kalbfleisch JD, Prentice RL, Prentice Ross L: The Statistical Analysis of Failure Time Data. New York, John Wiley \& Sons; 1980Chapter 2.

21. Akaike H: A new look at the statistical model identification. IEEE Trans Automatic Control 1974, 19:716-723.

22. Cox DR, Oakes D: Analysis of Survival Data. New York, Chapman \& Hall Ltd; 1984.

23. Altman DG, De Stavola BL, Love SB, Stepniewska KA: Review of survival analyses published in cancer journals. Bri J Cancer 1995, 72:511-518.

24. Moghimi-Dehkordi B, Safaee A, Pourhoseingholi MA, Fatemi R, Tabeie Z, Zali MR: Statistical comparison of survival models for analysis of cancer data. Asian Pac J Cancer Prev 2008, 9:417-420.

25. Hansson LE, Sparen P, Nyren O: Survival in stomach cancer is improving: results of a nationwide population-based Swedish study. Ann Surg 1999, 230:162-169

26. Manabu Y, Ayumi M, Toshifumi K: The Long-Term Outcome of Atomic Bomb Survivors with Gastric Carcinoma. J Surg Oncol 2009, 100:594-597.

27. Kulig J, Sierzega M, Kolodziejczyk P: Ratio of metastatic to resected lymph nodes for prediction of survival in patients with inadequately staged gastric cancer. Brit J Surg 2009, 96:910-918.

28. Ries L, Eisner MP, Kosary CL: Cancer Statistics Review: 1973-1989. NIH Pub. No. 92-2789. Bethesda: National Cancer Institute, USA; 1992:23:1-9.

29. Haugstvedt TK, Viste A, Eide GE, Söreide O: Norwegian multicentre study of survival and prognostic factors in patients undergoing curative resection for gastric carcinoma. The Norwegian Stomach Cancer Trial. $\mathrm{Br}$ J Surg 1993, 80:475-478.

30. Orsenigo E, Carlucci M, Braga M: Prognostic factors of gastric neoplasms: experience with 1,074 cases undergoing surgical treatment at a single center. Tumori 2005, 4(Suppl):S86-87.

31. Coburn NG, Swallow CJ, Kiss A: Significant regional variation in adequacy of lymph node assessment and survival in gastric cancer. Cancer 2006, 107:2143-2151.

32. Erturk MS, Ciçek Y, Ersan Y: Analysis of clinicopathological prognostic parameters in adenocarcinoma of the gastric cardia. Acta Chir Belg 2003, 103:611-615.

33. Shen JG, Cheong JH, Hyung WJ, Kim J, Choi SH, Noh SH: Influence of a microscopic positive proximal margin in the treatment of gastric adenocarcinoma of the cardia. World J Gastroenterol 2006, 12:3883-3886.

34. Karpeh MS, Leon L, Kimstra D, Brennan MF: Lymph node staging in gastric cancer: Is location more important than number? An analysis of 1,038 patients. Ann Surg 2000, 232:362-371.
35. Bozzetti F, Marubini E, Bonfanti G, Miceli R, Piano C, Gennari L: Subtotal versus total gastrectomy for gastric cancer: five-year survival rates in a multicenter randomized Italian trial. Ann Surg 1999, 230:170-178.

36. Sanchez-Bueno F, Garcia-Marcilla A, Perez-Flores D: Prognostic factors in a series of 297 patients with gastric adenocarcinoma undergoing surgical resection. Br J Surg 1998, 85:255-260.

37. Michelassi F, Takanishi DM, Pantalone D, Hart J, Chappell R, Block GE: Analysis of clinicopathologic prognostic features in patients with gastric adenocarcinoma. Surgery 1994, 116:804-810.

\section{Pre-publication history}

The pre-publication history for this paper can be accessed here: http://www.biomedcentral.com/1471-230X/11/1/prepub

doi:10.1186/1471-230X-11-1

Cite this article as: Zhu et al: Application of Weibull model for survival of patients with gastric cancer. BMC Gastroenterology 2011 11:1.

\section{Submit your next manuscript to BioMed Central and take full advantage of:}

- Convenient online submission

- Thorough peer review

- No space constraints or color figure charges

- Immediate publication on acceptance

- Inclusion in PubMed, CAS, Scopus and Google Scholar

- Research which is freely available for redistribution 